\title{
Gazetecilikte Artırılmış Gerçeklik Kullanımının Haber Kavramı Üzerinden Değerlendirilmesi
}

(Girişimcilik İnovasyon ve Pazarlama Araştırmaları Dergisi, 4(8), 153-165) Ebrar Feyza KILIÇ**

Öz

Geçmişten gelen birikim ve yeni fikirlerin üretimiyle hız kesmeden ilerleyen teknolojik gelişmeler, dördüncü sanayi devrimi tartışmaların ortaya çıkarmıştır. Sanayi 4.0'ın sanayileşmiş her sektörü değişime çekeceği konusu, faydalar ve zararları açısından ele alınmaktadır. Gazete işletmelerinin de medya sektörü içinde değerlendirilmesi, gazetelerin, gazetecilerin ve haber kavramının bu değişime ayak uydurmasının kaçınılmaz olarak görülmesinin bir göstergesidir. Bu çalışmanın amacl; geleneksel basıll gazetelerin teknolojiyle beraber değişimleri ve Sanayi 4.0 ile tanışması sonucu ortaya çıkan ve çıkabilecek ihtimallerin haber kavramı üzerinden değerlendirilmesi, haberin gerçeklik ilkesine ne gibi etkiler yaratabileceğini tartışmaktır. Bununla birlikte, çalışma, geleceğin gazetelerine ve araştırmacılara farklı bir bakış açısı sunmayı hedeflemektedir. Çalışmanın içeriği; haber kavramının geçmişi ve teknolojiyle ne gibi değiş̧imlere uğradı̆̆ı, gazetecilikte Sanayi 4.0 ile artırllmış gerçeklik kullanımının haber kavramı üzerinden değerlendirilmesi olarak seçilmiştir. Veri toplama tekniği olarak literatür taraması kullanılmıştır. Araştırma yöntemi olarak ikincil verilerden yararlanılarak üçüncül verilere ulaşılmış ve dördüncül verilere dayalı kurgusal analiz yapılmıştır.
\end{abstract}

Düzeltme Nedeni: Illk versiyonda üçüncü yazar ismi sehven makale yazarlarl kısmına eklenmiştir. Bu düzeltme versiyonunda yazarlardan üçüncü yazar ismi çıkartılmıştır.

Anahtar Kelimeler: Sanayi 4.0, Artırllmış Gerçeklik, Gazetecilikte Teknoloji, Haberde Artırılmış Gerçeklik.

\section{Evaluation of the Use of Augmented Reality in Journalism through News Concept}

\begin{abstract}
Technological developments, which progress without pausing with the experiences from the past and the productions of the new ideas, brought out the discussions of the fourth industrial revolution. The issue that Industry 4.0 will bring every industrialized sector to change is addressed in terms of its benefits and harms. The appraisement of the newspaper businesses within the media industry is an indicator of the consideration of newspapers, journalists, and the concept of news keeping up with this change as inevitable. The purpose of this study is to evaluate the possibilities of traditional print newspapers with technology and their introduction to Industry 4.0 through the concept of news, and to discuss the effects of news on the principle of reality. Moreover, the study aims to present a different perspective to future newspapers and researchers. The content of the study was chosen as the history of the news concept and the changes it has undergone with technology, the evaluation of the use of Industry 4.0 and augmented reality in journalism over the concept of news. Literature review was used for data collection. As a research method, tertiary data were obtained by using secondary data and fictional analysis based on quaternary data was employed.
\end{abstract}

Correction Reason: In the first version the third author is added to the authors by mistake. Thus, in the edited version, the third author is removed from the authors.

Keywords: Industry 4.0, Augmented Reality, Technology in Journalism, Augmented Reality in News.

*ORCID Doç. Dr., Çanakkale Onsekiz Mart Üniversitesi, Gazetecilik Bölümü, birolakgul@hotmail.com

**ORCID Y.L. Öğr., Çanakkale Onsekiz Mart Üniversitesi, Sosyal Bilimler Enstitüsü, ebrarfeyza.k@gmail.com 


\section{Extended Abstract}

Historical process studies show that the society has a dynamic structure. The reasons for the continuity of this dynamism are seen as natural events, geographical conditions, political, economic and technological developments - changes. The difference of systems, structures, change conditions and rate of change periodically shows that social change is a phenomenon.

This phenomenon and the augmented reality application used in the entertainment sector, which started to be mentioned together with Industry 4.0, are discussed in this study, as technological developments affect society, institutions and structures of the society, industrial revolutions create great changes in society and continue with new versions before they end.

Social changes continue and will continue to be associated with the discovery of nature and the desire to produce more efficiency on the inadequacy of the past by adding a new idea on every development. Regardless of material or spiritual space, products and thoughts are always formed this way. The transfer of these from person to person is by communication, that is, by communication. The emergence of the first newspapers in the $16^{\text {th }}$ century, it is known that people engaged in commerce in Venice were the only paper flyers received from the ports (Alver, 2007, p. 27). This information shows that curiosity needs to be informed and the need to know needs to be informed. With a micro level of thought, the economy is shaped in this direction. When viewed at the macro level, it is still argued whether the media or society shapes the media.

There is also news among the products that the media produces for consumption and presents to the society. The concept of news is considered as a fictionalized reality by definition. In the context of the media economy and ownership structures, it is thought that the reality in the news is suspicious as the technology is also involved in this situation. In this study, the effects of technology and technological developments, augmented reality applications and news on the reality of the news have been discussed in the context of technology, which is a phenomenon of social changes, to the $21^{\text {st }}$ century.

The subject of the study is a current and future subject. The study has been obtained from current data and by examining the applications. New comments were made by combining with the literature. These comments were created both conceptually and as a result of the current situation analysis.

The augmented reality application in news presentations is an application that increases the understanding for the news consumer. It enriches the news visually and in terms of information. However, any technological development and innovation does not increase the relationship of media products, especially news. It is thought that the augmented reality application used in news presentations, which is one of the new approaches in journalism developing with technology, does not cause a change in the relationship between news reality and only increases the credibility of the news. It is also predicted that this credibility will increase media manipulation and media deterrence.

The study shows that compared to the current situation analysis conducted in overseas media organizations in Turkey has actively start using the application. Media organizations need to follow and keep up with technology in terms of future research and development. It is believed that software and IT companies should be supported by holdings, which are media owners. 


\section{Giriş}

Tarihsel süreç incelemeleri toplumun dinamik bir yapıda olduğunu göstermektedir. $\mathrm{Bu}$ dinamizmin sürmesindeki sebepler ise doğa olayları, coğrafi şartlar, siyasal, ekonomik ve teknolojik gelişmeler- değişmeler olarak görülmektedir. Dönemsel olarak sistemlerin, yapıların, değiş̧me koşullarının ve değişme hızlarının farklılığı, toplumsal değişmenin bir olgu olduğunu göstermektedir.

Teknolojik gelişmelerin topluma, toplumun kurum ve yapılarına etki etmesi, sanayi devrimlerinin toplumda büyük değişimler yaratmasının ve bitmeden yeni versiyonlarıyla da günümüzde devam etmesi üzerine bu olgu ve Sanayi 4.0 ile beraber anılmaya başlayan genelde eğlence sektöründe kullanılan artırılmış gerçeklik uygulaması bu çalışmada ele alınmıştır.

Toplumsal değişmelerin bugüne kadar devam ediyor ve edecek oluşu, doğanın keşfiyle, her gelişmenin üzerine yeni bir fikir eklenmesiyle, eskinin yetersizliği üzerine daha verimlisini üretme isteğiyle bağdaştırılabilir. Maddi veya manevi alan fark etmeksizin ürünler ve düşünceler her zaman bu şekilde oluşmaktadır. Bunların insandan insana aktarımı ise iletişimle yani haberleşmeyle olmaktadır. İlk gazetelerin ortaya çıkış1 16. yüzyılda Venedik’te ticaretle uğraşan kişilerin limanlardan aldıkları tek kâğıtlık el ilanları olduğu bilinmektedir (Alver, 2007: 27). Bu bilgi merakın haber alma ihtiyacı ve bilinme isteği haber verme ihtiyacı doğurduğunu göstermektedir. Mikro düzeyde bir düşünceyle ekonomi bu doğrultuda şekillenmektedir. Makro düzeyde bakıldığında ise medyanın $\mathrm{m}$ ı toplumu, toplumun mu medyayı şekillendirdiği hâlâ tartış1lmaktadır.

Medyanın, tüketilmesi için üreterek topluma sunduğu ürünler arasında haberler de vardır. Haber kavramı tanımı gereği kurgulanmış gerçeklik olarak düşünülmektedir. Medya ekonomisi ve sahiplik yapıları bağlamında teknolojinin de bu durumun içine girmesiyle beraber haberdeki gerçekliğin şüpheye düştüğü düşünülmektedir. Bu çalışmada toplumsal değişmelerin bir olgusu olan teknolojinin 21. yüzyıla getirileri bağlamında, haber ve gerçeklik, haberde kullanılan teknolojik gelişmelerin, artırılmış gerçeklik uygulamalarının, haberin gerçekliğine olan etkileri tartışılmıştır.

\section{Artırılmış Gerçeklik}

Teknoloji, insan ve doğa ilişkisinin sonucunda ortaya çıkmıştır. İlkel ataların iş gücü için ürettiği ilk alet, ilkel teknolojinin başlangıcı olarak görülmektedir. Doğayı keşfedip ona hükmedebilme çalışmalarından sonra bitişi olmayan bir yarış başlamıştır. İnsanlık bu üretim yarışında birçok tarihsel değişime sebebiyet vermiştir. Sanayi devrimi olarak adlandırılan dönemler de buna örnek teşkil etmektedir.

Sanayi devriminin başlangıcı için literatürde araştırmacılar tarafından belirlenen net bir tarihten söz etmek zordur. Sanayi devrimi kavramı ilk olarak Fransızlar tarafından düşünülmüş olsa da genel kanıya göre, 18. yüzyılın son çeyreğinde buhar gücünü kullanmaya başlayan İngiltere'nin adıyla beraber anılmaya başlanmıştır. İkinci sanayi devrimi ise 1870'lerde elektriğin kullanımı ve seri üretimin fabrikalara yayılmasıyla başlamıştır. Bu süreci, soğuk savaş boyunca geliştirilen teknolojiyle kullanıma başlanan internet izlemiştir. 1940'lı y1llardaki bu dönem de üçüncü sanayi devrimi olarak isimlendirilmiştir (Özdoğan, 2019: 2-13).

18. yüzyılda başlayan ilk sanayi devriminin sonucunda toplumsal olarak büyük değişimler yaşanmıştır. Sosyolojinin ve psikolojinin yöntemsel araştırmalarını toplumla ve bireyle temellendirmesi, bu iki alanın bilim dalı olarak sayılmasına sebep olmuştur. İlk sanayi devriminin sosyoloji bilimini ortaya çıkarması, dönemin başlı başına devrimsel bir durum olduğu düşüncesini desteklemektedir. İşçi, ücret, boş zaman, mavi- beyaz yaka, sınıf, kentler, 
göç, hiyerarşi gibi olay ve olguların ortaya çıkışı, yeni bir toplum yaratmanın ayak sesleri olarak görülmektedir. Sisteme ayak uydurabilenin yaşamının kolaylaştığı, uyduramayanın ise sileceği düşüncesi, teknolojik tüm gelişmelerinin uyma isteğine yöneltmiştir. Kişisel yaşam tarzlarına dahi etki eden bu gelişmeler, üretim alanındaki sanayileşmiş her sektörde uyulması kaçınılmaz olarak görülmektedir.

Buharlı makine devrimi, elektrikli makine devrimi, internet devriminden sonra Almanya'da 2011 yılında düzenlenen Hannover Fuarı'nda ilk kez 'Sanayi 4.0' kavramı tartışılmaya başlanmıştır (Schwab, 2017: 16). Bu devrim için de literatürde akıllı devrim, dijital devrim, siber devrim gibi tanımlara rastlanmıştır. Yapay zekanın ön planda olduğu Sanayi 4.0; dijital ortama girilen her türlü işlemin ortak adı olan büyük verinin saklandığı ve donanımların ortak kolayca ulaşılabildiği bulut bilişim sisteminin, otonom robotların, üç boyutlu yazıcıların, simülasyonların, nesnelerin internetinin ve artırılmış gerçekliğin kullanılmaya başlandığı ve geliştirilmeye devam ettiği yeni bir dönemi kapsamaktadır. Bu dönemin, üretimi ve tüketimi baştan sona değiştirmesi ve toplumda büyük değişimler sonucu oluşan anomiler ortaya çıkarması beklenmektedir. $\mathrm{Bu}$ yorum, sosyolojik bir bakışla, tarihteki diğer devrimlerin yarattığı etkiler sonucunda gözlemlenerek öngörülen negatif bir yorumdur. Ekonomide yol açabileceği negatifliklere bu çalışmanın konusu olmadığı için değinilmemiştir. Lakin sadece olumsuz tarafları da burada ele alınmamıștır. Sanayi 4.0 sürecinin pozitif etkileri de araştırmacılar tarafından değerlendirilmiştir. Bu bölümde çalışmanın konusu olan artırılmış gerçeklik kavramının tanımı, işleyiş biçimi ve uygulandığı alanlar ele alınmıştır.

İngilizce'de augmented reality'nin (AR) karşılığı Türkçeye artırılmış gerçeklik olarak geçmiştir. Kavramla ilgili birçok tanımı mevcut olmakla beraber bunlardan ilki; 'Artırılmış gerçeklik, gerçek dünyadaki çevrenin ve içindekilerin, bilgisayar tarafından üretilen; ses, görüntü, grafik ve GPS verileriyle zenginleştirilerek meydana getirilen canlı veya dolaylı fiziksel görünümüdür. Bu kavram kısaca gerçekliğin bilgisayar tarafından değiştirilmesi ve artırılmasıdır. Teknoloji kişinin gerçekliğini zenginleştirme işlevini görür' (Wikipedi). 'Kullanıcı, gelişen artırılmış gerçeklik teknolojisinin de yardımıyla etraftaki bilgi ile etkileşime girebilir. Bahsi geçen sayısal bilgi işlenmeye elverişlidir. Bulunulan çevreyle ilgili yapay bilgi ve öğeler gerçek dünyayla bağdaşabilir' (Önday, 2017: 66). Bir başka tanımı ise; 'Google Glass da dahil olmak üzere eski artırılmış gerçeklik konseptleri, aynalar aracılığıyla yansıtılan veya görüş alanı içine aksettirilen küçük ekranlara dayanır' (King, 2016: 217). Eğlence alanında karşımıza çıktığı, Instagram ve SnapChat efektleri; oyun alanında ise PokemonGo örnekleri verilebilir. Artırılmış gerçeklik görüş alanının içine yansıyan göz hizası içindeki teknoloji türüdür, örnek olarak Magic Leap ve Microsoft HoloLens gibi teknolojiler verilebilir (King, 2016: 218). Diğer bir tanımda ise AR kamera veya optik görüntülerinde algılanan mekâna ekleme yapılarak görüntü iliştirmek olarak geçmektedir (Carmigniani, 2011: 344).

Kısaca artırılmış gerçeklik; gerçek hayatın üzerine gerçek dünyadan soyutlamadan inşa edilen, karşılıklı etkileşimi mümkün olan, sanal olan gerçeğin yerini tamamlayan, herhangi mobil uygulama gibi kullanılabilen, tamamen kurgusal bir görünüm olarak tanımlanabilir.

Artırılmış gerçekliğin tarihçesi 1901 yılında Frank Baum'un gerçek hayata veri aktaran elektronik ekranlardan bahsetmesiyle başlamıştır. 1960'da üretilen simülatör makinesi, 1968'de üretilen kafaya takılan ekran teknolojinin geliştirilmesi, 1982'de ilk defa televizyonda hava olayları için kullanılan sunumun AR ile görselleştirilmesi, 1992'de ilk defa Tom Caudell tarafından artırılmış gerçeklik kavramının kullanılması, 1998'de ABD'de ilk defa üç boyutlu AR teknolojinin gelişmesi, 2004'de BBC kanalında yayınlanan Bamzooki çocuk programında AR uygulamasının kullanımı örnek teşkil etmektedir (Yöndem ve Karadağ, 2019: 26-27). 
Ronald T. Azuma'nın Artırılmış Gerçeklik Araştırması (1997) adlı makalesinde artırılmış gerçeklik; gerçek dünyanın görülmesine izin verilen, sanal nesnelerin üzerine yerleştirilen veya gerçek dünyayla birleştirilen sanal gerçeklik uygulamasının bir varyasyonu olarak tanımlanmaktadır. Tıbbi görüntüleme, üretim ve onarım, açıklama ve görselleştirme, robot yönetimi, eğlence ve askeriyede artırılmış gerçeklik uygulanabilmektedir. Artırılmış gerçeklik uygulaması optik ve video temelli olarak ikiye ayrılmaktadır (355-364). Optik olarak takılabilir artırılmış gerçeklik gözlükleri olan Sony SmartEyeglass, Epson Moverio BT-200, Recon Jet, Google Glass gibi Resim 1'deki görsel örnek verilebilir. Video temelli artırılmış gerçeklik uygulamaları ise monitör vasıtasıyla yani ekranı olan bilgisayar, televizyon, mobil telefon, tablet gibi araçlarla görüntülenmektedir. Kayıt esnasında kurgulanan animasyon, simülasyon gibi eklemelerle yapılmaktadır. Resim 2'deki görsel buna örnektir.

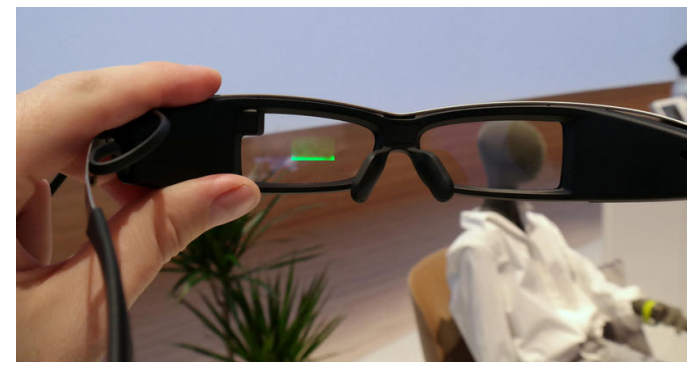

Resim 1: Sony SmartEyeglass optik temelli AR gözlüğü (URL 1).

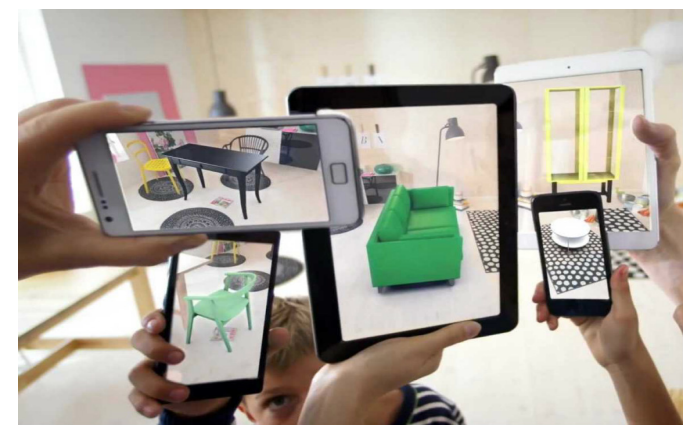

Resim 2: Video temelli İKEA markasının uyguladığı AR uygulaması (URL 2).

\subsection{Artırılmış Gerçekliğin Dilsel Tanımı}

Artırılmış gerçeklik uygulaması yukarıda tanıtılmıştır. Bu bölümde çalışmanın bağlamı kapsamında kavram üzerinden bir değerlendirme yapılmıştır. Türkçe'ye artırılmış gerçeklik olarak çevirinle bu kavram semantik açıdan irdelenmiştir. Öncelikle gerçek üzerinde durulmuş, sonrasında artırmak üzerinden tanımlama yapılmıştır.

Gerçek, Türk Dil Kurumu sözlüğüne göre; 'Yalan olmayan, doğru olan şey, hakikat' anlamına gelmektedir. Diğer anlamı 'Bir durum bir nesne veya bir nitelik olarak var olan, varlığı inkâr edilemeyen, olgu durumunda olan' olarak geçmektedir. Gerçek felsefi olarak metafiziğin konusudur ve felsefenin ilk sorularından tartışma konularının arasında yer alır. Immanuel Kant'a göre gerçeklik, duyuların dışında varlığı mutlak olan şeydir. Doğru ve yanlış ise zihin süzgecinden geçen tanımların ifade şeklidir (Warburton, 2017: 167-171). Arthur Schopenhauer'a göre ise gerçeklik iki türlüdür. Birincisi irade olarak adlandırdığg her şeyde mutlak surette bulunan itici güç, örneğin bitkileri ve hayvanları büyüten enerjidir. İkinci olarak tasarımdır bu da insanların deneyimiyle elde ettiği bildiği dünyadır (Warburton, 2017: 202). Aydınlanma filozofları olan Hobbes ve Leibniz'in maddesel olanın gerçek olduğunu 
savundukları bilinmektedir. Kısaca, duyular dışında varlığı sabit olan, zaman ve mekandaki icat edilmeyen ama keşfedilebilen şeye ya da maddesel olarak var olan şeye gerçek denmektedir.

Artırmak, Türk Dil Kurumu sözlüğüne göre; 'Artmasını sağlamak, çoğaltmak' anlamına gelmektedir. Toplama işleminin sembolü artıdır. Bir şeyi fazlalaştırmak, üzerine eklemek için artırma işlemi yapılmaktadır. Yani olan bir şeyi çoğaltmaktır. Anlam olarak incelenmek için kelimelerine ayrılan artırılmış gerçeklik kavramı, yukarıdaki tanımlar değerlendirildiğinde Türkçe karşılığı uygun bir kavram mı sorusu ortaya çıkmaktadır. İkinci olarak da gerçeğin artırılması mümkün müdür sorusu sorulabilir.

Dijital Dönüşüm adlı kitapta augmented reality’nin, zenginleştirilmiş gerçeklik olarak çevrisinin yapıldığı görülmüştür (Önday, 2017). Zenginleştirilmiş gerçeklik çevirisi, görsel ve işitsel unsurların daha fazla kullanılmasının etkisi değerlendirilerek oluşturulmuş bir tanım olarak görülmektedir. Uygulamanın temeli zaten sanal olan şeylerin gerçek olanla birleştirilmesi ve deneyimini artırmaktır. Sanal kavramının zıttı gerçektir. Sanal gerçeklik olarak adlandırılan uygulamanın da geliştirilerek artırılmış gerçeklik uygulamasını yarattığı bilinmektedir. Sanal olanın maddesel olarak değil ama teknolojik bir araçla dijitale aktarımı ile gerçekleştirilen sanal gerçeklik, gerçek olmayanın -zihinde olanın- gerçekliği anlamına gelmektedir. Gerçekliğin sanalı yapılmış ve gerçekliğin gerçekliği artırılmıştır. Burada görülen gerçek kavramının tamamen değişime uğramış oluşudur. Gerçek artık değişmektedir. Tamamen kurguyla ve dijital ortamda, gerçekliğin kültürel kodlarından yararlanan bu uygulamanın 'kurgulanmış gerçeklik' veya 'aracılanmış gerçeklik' olarak tanımlanması doğasına daha uygun olarak görülmektedir.

\section{Haber Kavramı ve Gerçeklik İlişkisi}

Haber, Türk Dil Kurumu sözlügüne göre; 'Bir olay, bir olgu üzerinden edinilen bilgi' anlamına gelmektedir. Diğer anlamı 'İletişim veya yayın organlarıyla verilen bilgi' olarak geçmektedir. 'Toplumda veya tabiatta meydana gelen çeşitli olay, durum ve görünümle ilgili bilgi ve duyurulara haber denir' (Tayfur, 2018: 11). Tokgöz'e göre, 'Haber, herhangi bir zamanda geçen olay, fikir ya da sorunun özetidir'. Wilbur Schramm' a göre, 'Haber bir olay değildir, olduktan sonra algılanabilecek bir olgudur, olayla özdeş değildir, fakat olayın esas çerçevesi içinde tekrar kurulabilmesi hedefidir'. Van Dijk'e göre haber, toplumda var olan egemen söylemlerin bir ürünüdür. Stuart Hall'e göre ise haber, egemen söylemlerin yeniden üretildiği metinlerdir (Tokgöz, 2019: 213-224). İletişim ve gazetecilik biliminde evrensel bir haber tanımı söz konusu değildir. Araştırmacıların her biri kendi alanlarına göre haberi dilsel, toplumsal, ekonomik, ideolojik temeli tanımlarını yapmıştır. Ayrıca her yorumun da bağlamına göre haklı olduğu düşünülmektedir. Zamana ve mekâna bağlı olarak, geniş toplumsal kesimleri doğrudan ilgilendiren olayların bir gazeteci tarafindan profesyonel kurallara uyularak yazıldığı metnin, kitle iletişim araçlarıyla tüketime sunulduğu, enformasyonun şekillenmiş haline haber denmektedir.

Gaye Tuchman'a göre ise haber kurgulanmış gerçeklerdir (Tokgöz, 2019: 213). Haberin gerçekle ilişkisi tartışılan bir konudur. Yukarıda yapılan gerçeklik tanımına göre haber var olan olguların, olayların, durumların yorumlanmış hali olarak tanımlanabilir. Haberin hammaddesi olaydır, haber eskir, olay eskir ama olgular gerçekliğin kendisidir. Gerçeklik üretilmez, keşfedilir ama haber üretilir. Walter Lippmann'a göre haberin işlevi olayı iletmekken gerçeğin işlevi olguları gün 1şığına çıkarmaktır (Tokgöz, 2019: 221). Haber üretim süreci başından sonuna normatif bir çizgide ilerler. Bir olayın dikkat çekiciliği haber değerini ifade eder ve gerçekleşen olaylar haber yapılmak için seçime tabi tutulur. Bu seçim gazeteciye, gazete sahiplik yapısının ekonomi politik duruşuna göre veya kültürün dildeki sembolik yansımalarına 
göre değişiklik göstermektedir. Yapısal yanlılık olarak adlandırılan bu durum haberin gerçekle ilişkisini taraflılık olarak değerlendirmekte ve haberin tam olarak gerçeği temsil etmediğini ifade etmektedir. Haberi çerçeveleme, öne çıkarma ve gündem belirleme kuramlarına göre de haber gerçeklik ilişkisi tartışmaya açık hale gelmektedir.

"Meydanın bize sunduğu hiçbir şey gerçek değildir. Herhangi bir gerçeğin birileri tarafından başka gerçekler arasından seçilmiş, ayrıntılardan arındırılmış, teknik kısıtlara göre sunulabilir hale sokulmuş biçimidir" (Kıvanç, 1995'ten aktaran; Yurdigül,2011: 16). Bu bağlamda değerlendirildiğinde televizyon haberciliğinin ortaya çıkışıyla basılı gazetelerin güven kaybettiği düşünülmektedir. Televizyon haberciliğindeki video akışı, haberi canlı yayınla verme, son dakika olarak geçme, haber sunumunda kullanılan fotoğraflar ve haber olayının kayıtları bu düşünceyi destekler niteliktedir. Haber doğası gereği bayatlamaktadır. Basılı gazeteler ise bu bayatlamanın önüne geçmek için haberi gündemde tutmaya çalışmaktadır.

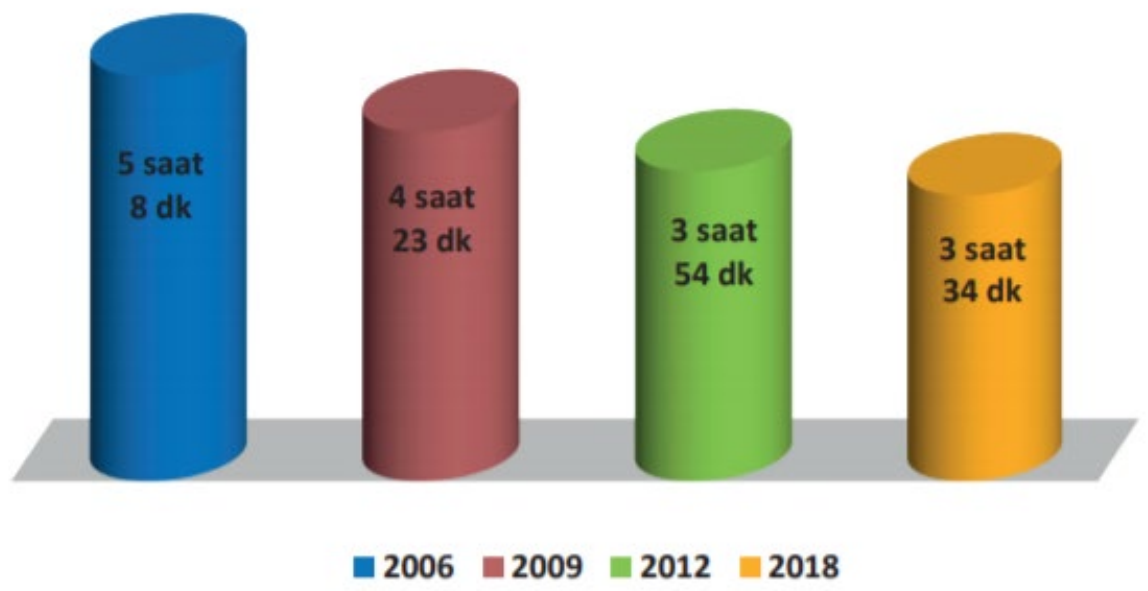

Resim 3: Günlük ortalama televizyon izleme süresi karş1laştırması (URL 3).

Bireylerin gerçeklik algısını oluşturmasında medyanın gücünün göz ardı edilemeyeceği düşünülmektedir. Psikolojik olarak bireyin öğrenimi ilk önce ailede başlamakta, sonrasında yakın çevre ve okulla devam etmektedir. Teknolojinin gelişimiyle beraber televizyon, cep telefonu ve bilgisayarlar da aile bireyi olamaya başlamış ve bilişsel öğrenmedeki payı artmıştır. Resim 3'teki grafik Radyo ve Televizyon Üst Kurulu'nun yapmış olduğu, Televizyon İzleme Eğilimleri Araştırması verilerine göre yıllar bazında günlük ortalama televizyon izleme sürelerinin karşılaştırmasıdır. Geçmiş yıllardan yakın döneme izleme saatinin düştüğü görülmektedir. Bunun nedeni, yeni medya araçlarının televizyondan daha çok kullanılmaya başlaması olarak görülmektedir. Cep telefonları internete bağlanabildiği sürece televizyonun ve gazetenin yerine geçebilmektedir. Günlük televizyon izleme saatlerinin ve basılı gazetelerin tirajlarının düşmesinin sebebi bu durum olarak görülmektedir.

Yeni medyanın ortaya çıkışıyla gazetelerin dijital ortamda yayın yapması son dakika haber girebilme, haberin içeriğine video ve çok fazla görsel ekleme imkanı tanımıştır. $\mathrm{Bu}$ kullanış açısından basılı gazeteden daha çok tercih edilmektedir. Haberin gerçeklikle olan ilişkisini diri tutmayı daha mümkün kılmıştır. Bir gerçekliğin değiştirilmeden aktarımı, aktaran aracın saydamlığına bağlıdır. İletişim araçları teknik olarak bu saydamlıktan uzaktır. Bir olayın aktarım için seçilmesi ve dilsel olarak yazıya dökülmesi veya kurgulandıktan sonra yayınlanması bu gerçekliği örtmektedir (Yurdigül, 2011: 20). Bu bölümde teknolojinin etkisiyle değişen haber sunumlarının örneklerine değinilmiştir. 


\section{Gazetecilikte Artırılmış Gerçeklik Uygulamaları}

Dijitalleşmeyle beraber habercilikte yeni yaklaşımlar aranmaya başlanmıştır. Gazetelerin web sayfalarından ve mobil uygulamalarından ürettiği haber içerikleri basılı gazetedeki bir haberden daha çok bilgi vermektedir. Bunun sebebi; fazla görsel kullanabilme, video ekleme, okuyucunun yorum yapabilmesi, haberi teyit edebilme gibi özelliklerinin olmasıdır. Artırılmış gerçeklik uygulaması ise geleneksel gazetecilikte video temelli olarak kullanılmaktadır. Buna Türkiye'den örnek olarak Resim 4'teki Hürriyet gazetesinin uygulaması örnek verilebilir. Lakin bu örnek bir haber sunum değil, reklam filmi oynatımıdır.

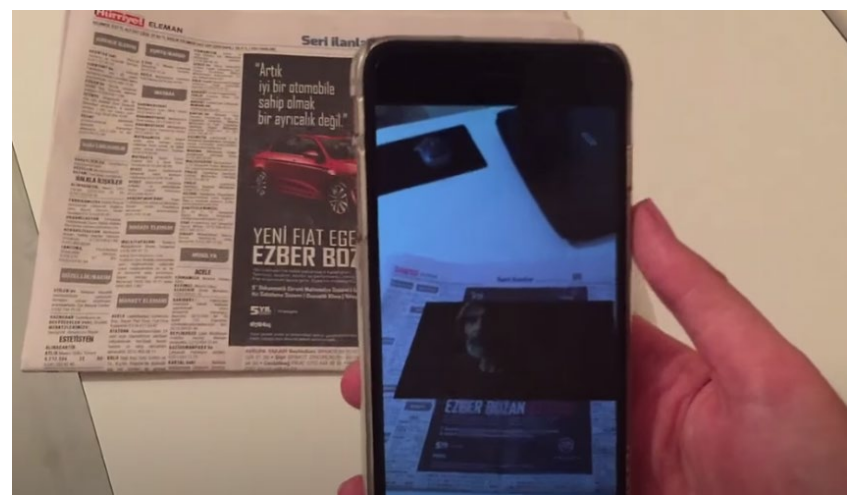

Resim 4: Hürriyet gazetesinin video temelli reklam uygulaması (URL 4).

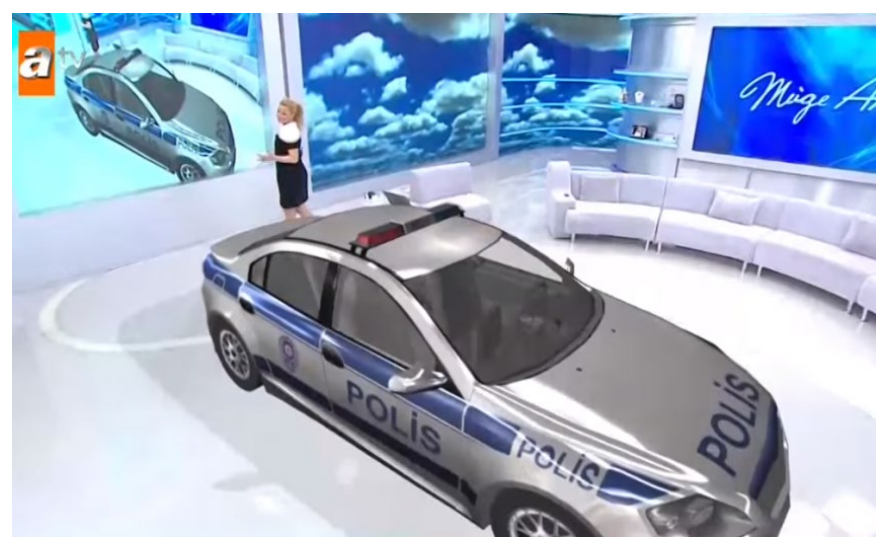

Resim 5: Müge Anlı programında AR uygulamasını tanıtırken (URL 5).

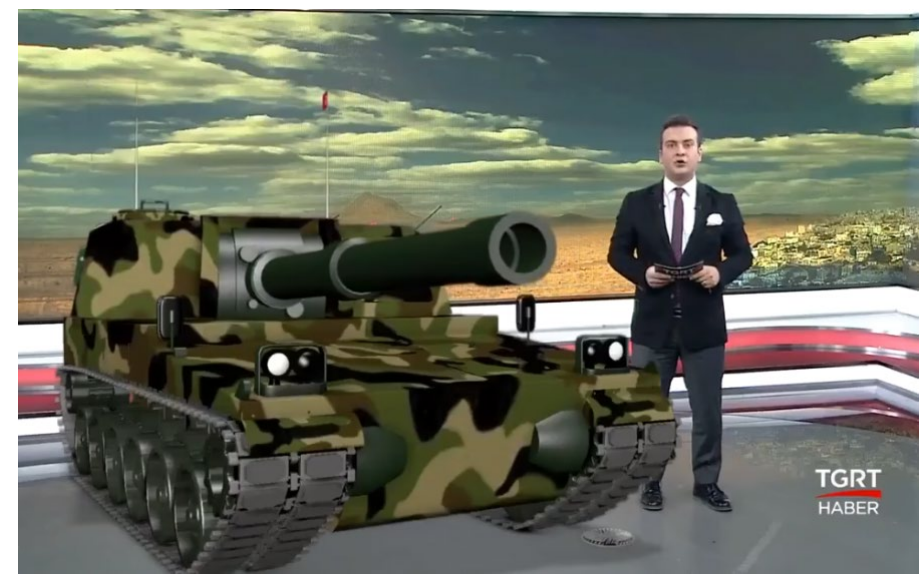

Resim 6: TGRT Haberdeki bir AR uygulaması (URL 6). 
Sosyal medya, yeni medya gibi ortamlarda iletişimin gerçekleştiği, haber alışverişinin yapıldığı, reklamcılığın kolaylaştığı Google, Yahoo, Facebook ve Twitter gibi sitelerin yükselişinin, gazetelere olumsuz etkileri sonucunda AR uygulamalarına gidilmiştir (Pavlik, 2013: 7). Türkiye'de artırılmış gerçeklik uygulamaları, gazetelerde ve televizyon haber sunumlarında aktif olarak kullanılmaya başlanmamıştır. Resimlerdeki örnek uygulamalar sadece bir denemede kalmıştır. AR uygulamaları geleneksel gazetecilik ile medya, bilgisayar ve bilgi birleşiminden doğmaktadır. Gazetelerde genelde QR (Quick Response) kodları kullanılmaktadır. Telefon, tablet gibi cihazlara indiren kod okuyucu uygulamalar aracilığıyla reklam veya haberler oynatılabilmektedir. Junaio ve Aurasma akıllı mobil cihazlar için tasarlanmış bir AR tarayıcısıdır. Wall Street Journal ve New York Times, Aurasma'yı mobil medyayı basılı gazete ürünüyle entegre etmek ve mobil AR haber deneyimi için bir araç olarak kullanmıştır. Aurasma aracılığıyla, bir gazeteye veya dergiye işaret eden kamera donanımlı bir akıllı telefon veya tablet, iki boyutlu bir görüntüyü tanıyabilir, kaydedilmiş bir video veya 3 boyutlu nesneyi hatırlayabilir ve üzerlerine ses de ekleyebilmektedir (Pavlik ve Bridges, 2016: 10-12).

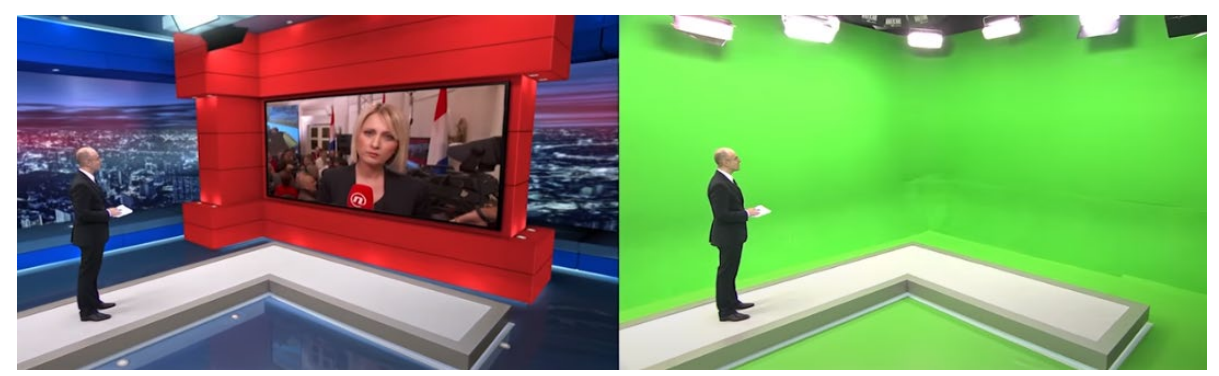

Resim 7: Nova TV’de (Hırvatistan) yeşil perde kullanımıyla yapılan AR (URL 7).

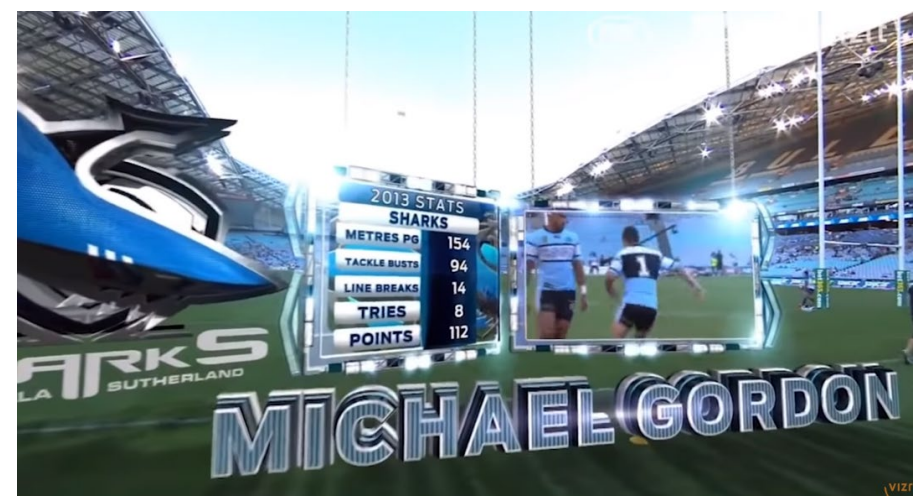

Resim 8: Fox Sport’un canlı yayın görüntüsüne yerleştirdiği AR (URL 8).

Televizyon haberciliğindeki uygulamaları ise haber sunumuna farklı bir soluk getirmiştir. Yeşil perde stüdyolarında (Resim 7) veya canlı yayın görüntüsüne bilgisayarlar aracılığıyla yerleştirilen üç boyutlu objelerle (Resim 8) uygulandığı görülmektedir. Televizyondaki haber sunumlarında kullanılan AR uygulaması genel olarak coğrafi grafikler, haber içinde senkronize edilmiş fotoğraf ve videolar, üç boyutlu objeler eklenerek daha fazla ayrıntı sunumuna gitmektedir. Tamamen bilgisayar aracılığıyla kurgulanmış bir haberin canlandırması yapılmaktadır. AR sunumu esnasında, sunucu sanki o anı stüdyoda yaşıyor gibi oyunculuk yaparak haberi anlatmaktadır.

Medya şirketinin, AR uygulamasını kullanabilmesi için teknolojik imkanlara sahip olması veya bir yazılım şirketiyle ortak çalışıyor olması gerekmektedir. Yurtdışın AR uygulaması kullanan kanallar ve gazeteler aşağıda verilmiştir. Yapılan araştırma sonucunda ABD ve Batı'daki birçok medya kuruluşunun, Norveç kökenli 'Vızrt' isimli içerik üreticisi ve 
dağıtıcısı olan yazılım markasından içerik aldığı bulgusuna varılmıştır. Yine bir diğer marka Çin kökenli 'Uni-Leader' Asya ülkeleri için içerik üreten teknoloji ve yazılım şirketidir.

AR uygulayan yabancı gazete örnekleri New York Times, USA Today, Wall Street Journal, Boston Globe, Financial Times, The Times, The Sun, Daily Telegraph gibi birçok isimken, Türkiye'de sadece Hürriyet Gazetesi deneme için bir kez kullanmıştır (Kaynak: Youtube).

AR uygulayan yabancı televizyon kanalı örnekleri Al Jazeera, America's Morning Headquarters, ARD Almanya, BBC, CBC News Kanada, Fox Sport ABD-Avusturalya, Globosat Brazilya, IBC Filipinler, MBC Güney Kore, Nova TV Hırvatistan, Televisa Meksika, The Weather Channel, ABD Univision Deportes Network ABD, TV 2 Danimarka gibi birçok isimken; Türkiye'de sadece ATV ve TGRT deneme örnekleri mevcuttur (Kaynak: Youtube).

Medyanın içinde değerlendirilen radyonun AR uygulamasını kullandığı örnekler bulunamamıştır. Uygulamanın işleyiş biçimi ve kendisi zaten görsellik üzerine olduğu için sadece işitsel olarak hitap eden radyoda AR'nin kullanımı mümkün görülmemektedir. Tabii ki gelişen teknoloji bu durumu da ilerde değiştirebilir.

\section{Gerçekliği Artırılmış Haberin Değerlendirilmesi}

Medya ürünleri, teknoloji, bilim ve bilginin harmanlanarak ortaya çıkarıldığı habercilikte kullanılan artırılmış gerçeklik uygulamaları yukarıdaki başlıklarda ayrıntılı olarak işlenmiştir. Çalışmanın amacı AR uygulamalarının haberciliğe kattığı artı ve eksileri ortaya koyup, haber kavramının gerçeklik ilişkisi bağlamında AR uygulamalarıyla beraber değerlendirilmesidir. Aşağıdaki tabloda haberde artırılmış gerçeklik kullanımının haber üzerindeki olası olumlu ve olumsuz etkiler yer almaktadir:

Tablo 1: Haberde AR Kullanımının Haber Üzerindeki Olası Etkileri

AR Kullanımının Habere Olumlu Etkileri
- Görselliği ve işitselliği artırır.
- Odaklanmayı ve anlamayı
kolaylaştırır.
- Deneyimi mümkün kılar.
- Çabuk unutmayı engeller ve
kalıcılığı sağlar.
- Pozitif caydırıcılığı artırır.

AR Kullanımının Habere Olumsuz Etkileri

- Manipülasyona açık hale getirir.

- Propaganda yapımını kolaylaştırır.

- Negatif caydırıcilığı artırır.

- Haber sunumunu dramatikleştirir.

- Doğru olmayan şeylerin kabulünü artırır ve algıyı değiştirir.

- Ekonomik açıdan eşit ulaşımı

Habercilikte kullanılan QR kodlu ve video temelli uygulamaların sonucunda ortaya 'gerçekliği artırılmış haber' tanımı çıkmaktadır. Haber gerçeklik ilişkisi bağlamında haberin gerçekliğini artırmak ne kadar mümkündür sorusunun cevaplanması gerekmektedir. Haber tanımı gereği gerçeğin tekrar yazımı olarak değerlendirildiğinde, haberin gerçek olanı tam yansıtmadığı ortadadır. Teknolojinin gelişmesiyle ve medya sektörünün buna ayak uydurmasıyla basılı gazeteden radyoya, televizyondan etkileşimli medyaya, medya tüketicisinin üreteci olduğu bir döneme gelinmiştir. İşitselliği ve görselliği artan haberlerin inandırıcılığg ve gerçek olduğu düşüncesi de artmaya başlamıştır.

Habercilikte AR uygulamasının pozitif yönü, medya ürünü tüketicisinin olayı daha iyi kavramasına fayda sağlamaktır. Haber sunumunun bir bakıma eğlenceli hale gelmesi, habere 
odaklanmayı artırabileceği düşünülmektedir. AR uygulamaları bu noktada haberi yaşatma boyutuna gelmiştir. Daha doğrusu haber tüketicisi henüz haberi yaşadığı bir teknolojik zamanda değildir. Haber üreticilerinin haberi bir tiyatro gibi canlandırması ve bir film gibi kurgulayarak servis etmesi söz konusudur. Haber sunumunda kullanılan grafik, animasyon, üç boyutlu objelerin içinde gerçekmiş gibi yaşayan muhabirin, negatif boyutta haberin profesyonel kurallarına aykırı davranıldığı düşünülmektedir. Haber yazım kuralları evrensel olarak belirli dilbilgisi kalıplarında edebi eserlerden ayrılması için normatif kurallara tabi tutulur. Bu kuralın sadece gazetecilik alanında değil televizyon haberciliği alanında geçerli olması gerekir. Haber üretim sürecinden gelen kurgusallı̆̆a, yayın esnasında kullanılan bilişim teknolojilerinin kurgusallığı da eklenmiştir. Haber sunumuna AR uygulanmasıyla haberin gerçekle olan ilişkisini artırmak söz konusu değildir. Bu durum habere konu olan olayın ne gerçekliğini artırır ne de gerçekliğini azaltır. Sadece sunumsal olarak farklı bir teknolojinin kullanılması, haberin gerçekliğine olan inancı artırır. Artırılmış gerçeklikle haber sunumunun ortaya çıkardığı, bu çalışmada üretilen 'gerçekliği artırılmış haber' tanımı kavramsal olarak yanlıştır. Çünkü haber kavramının kendisinde artan ya da eksilen bir şey söz konusu değildir. 'Görselliği artırılmış haber' olarak tanımlanması daha doğru görülmektedir.

Basılı gazetelerin, dijitalleşmeyle beraber ilerleyen senelerde ortadan kalkacağı veya dönüşüme uğrayacağı öngörüleri mevcuttur. Türkiye'deki gazete işletmelerinin bu öngörü doğrultusunda AR uygulamalarına para harcamadığı düşünülmektedir. Ayrıca gazete sahiplik yapılarındaki holding patronlarının, toplumun bazı kesimlerinin geleneksel gazetelere olan bağından ötürü de bu değişime gitmek istemedikleri düşünülebilir. Bir diğer eksiklik olarak da Türkiye'deki teknoloji ve yazılım şirketlerinin habercilik alanında yeni içerikler üretip medya kuruluşlarına sunmadığı ya da medya kuruluşlarının içerik üreticilerinden AR'yi talep etmediği düşünülmektedir. Yurtdışındaki uygulama sayısıyla Türkiye kıyaslandığında çok büyük bir fark vardır. Türkiye, habercilikte AR uygulamasını kullanmakta geç kalmıştır.

Teknoloji, ekonomik boyutta yüksek meblağlar sonucunda elde edilmektedir. Medya kuruluşların değişen ekonomi ve siyaset sonucunda holdingleşmeye gittiği tarihsel süreçte bilinmektedir. Holdingler enerji, sanayi, iletişim alt yapısı, teknoloji gibi farklı sektörleri bünyesinde barındırırken, medya sektöründe AR uygulamalarına geçiş yapmamaları, bu alana yatırım yapmadıklarını gösterir. Yapılan incelemede Türkiye'deki birçok yazılım şirketinin internet sitelerinde AR ile ilgili çalışmalarını sunduğu görülmektedir ama bu uygulama genel olarak eğlence için üretilmekte ve kullanılmaktadır. Bu inovasyonun gerçekleşmesi için teknoloji, yazılım ve bilişim şirketlerinin desteklenmesi ve medya kuruluşlarının bu sürece dahil edilmesi önerilmektedir.

\section{Sonuç}

Çalışmanın konusu güncel ve geleceği olan bir konudur. Çalışma güncel verilerden ve uygulamaların incelenmesiyle elde edilmiştir. Literatürle birleştirilerek yeni yorumlar yapılmıştır. Bu yorumlar hem kavramsal olarak hem de mevcut durum analizi sonucunda oluşturulmuştur.

Haber sunumlarındaki artırılmış gerçeklik uygulaması haber tüketicisi açısından kavrayışı artıran bir uygulamadır. Haberin görsel açıdan ve bilgi açısından zenginleştirmektedir. Lakin herhangi bir teknolojik gelişme ve inovasyon, başta haber olmak üzere medya ürünlerinin gerçekle olan ilişkini artırmamaktadır. Teknolojiyle beraber gelişen habercilikte yeni yaklaşımlardan bir tanesi olan, haber sunumlarında kullanılan artırılmış gerçeklik uygulamasının, haber gerçeklik ilişkisinde bir değişime sebep olmadığı, sadece 
haberin gerçekliğine inandırıcılığı artırdığı düşünülmektedir. $\mathrm{Bu}$ inandırıcılığın medya manipülasyonunu ve medya caydırıcılığını artıracağı da öngörülmektedir.

Çalışmada yapılan mevcut durum analizi göstermektedir ki yurtdışına kıyasla Türkiye'deki medya kuruluşları aktif olarak bu uygulamayı kullanmaya başlamamıştır. Geleceğe yönelik araştırma geliştirme açısından medya kuruluşlarının teknolojiyi takip etmesi ve ayak uydurması gereklidir. Bunun için yazılım ve bilişim şirketlerinin medya sahipleri olan holdingler tarafından desteklenmesi gerektiği düşünülmektedir.

\section{Kaynaklar}

Alver, F. (2007). Gazeteciliğin Kuramsal Temelleri, İstanbul: Beta Kitap.

Azuma, R. T. (1997). "A Survey of Augmented Reality", Massachusetts Institute of Technology, 6(4), s. 355-385.

Carmigniani J., Furht B., Anisetti M., Ceravolo P., Damiani E., Ivkovic M. (2011). “Augmented Reality Technologies, Systems And Applications”, Multimed Tools Appl, 51, s. 341-377.

King, B. (2016). Augmented, (Çev.) Balaban, K., İstanbul: MediaCat.

Önday, Ö. (2017). Dijital Dönüşüm, Ankara: Gazi Kitabevi.

Özdoğan, O. (2019). Endüstri 4.0, İstanbul: Pusula Yayıncılık.

Pavlik, V. J. (2013). "Trends in New Media Research: A Critical Review of Recent Scholarship", Sociology Compass, 7(1), s. 1-12.

Pavlik, V. J. ve Bridges, F. (2016). "The Emergence of Augmented Reality (AR) as a Storytelling Medium in Journalism”, Journalism \& Communication Monographs, 15(1), s. 4-59.

Schwab, K. (2017). Dördüncü Sanayi Devrimi, (Çev.) Dicleli, Z., İstanbul: Optimist Yayın.

Tayfur, G. (2018). Haber Toplama, Yazma ve Yayınlama Teknikleri, Konya: Eğitim Yayınevi. Tokgöz, O. (2019). Temel Gazetecilik, Ankara: İmge Kitapevi.

Yöndem, T. ve Karadağ, G. H. (2019). “Artırılmış Gerçeklikle Değişen Haber Sunumu”, Yeni Medya Elektronik Dergi, 3 (1), s. 22-44.

Yurdigül, Y. (2011). "Kurgusal Gerçeklik Bağlamında Haber ve Gerçeklik İlişkisi”, Atatürk Illetişim Dergisi, (1), s. 13-24.

Warburton, N. (2017). Felsefenin Kısa Tarihi, (Çev.) Ateşoğlu, G., İstanbul: Alfa Basım Yayım.

URL 1: http://www.teknolo.com/10-artirilmis-gerceklik-gozlugu/ (Erişim Tarihi 12.04.2020).

URL 2: https://www.endustri40.com/artirilmis-gerceklik-kullanan-7-marka/ (Erişim Tarihi 12.04.2020).

URL3:https:/www.rtuk.gov.tr/assets/Icerik/AltSiteler/televizyonizlemeegilimleriarastirmasi2 018.pdf (Erişim Tarihi 15.04.2020).

URL 4: https://www.youtube.com/watch?v=kzk8dXoTj1s (Erişim Tarihi 15.04.2020).

URL 5: https://www.youtube.com/watch?v=bbP_gtCcWjs (Erişim Tarihi 15.04.2020).

URL 6: https://www.youtube.com/watch?v=_Idy0izevN8 (Erişim Tarihi 15.04.2020).

URL 7: https://www.youtube.com/watch? $\mathrm{v}=7 \mathrm{hJS} 21 T 3$ gnc $\& \mathrm{t}=14 \mathrm{~s}$ (Erişim Tarihi 15.04.2020).

URL 8: https://www.youtube.com/watch?v=uN221GhLmZI (Erişim Tarihi 15.04.2020). 